\title{
On the Nature of the 'Lethal Zygote' produced by Crossing Non-Colicinogenic with Colicinogenic Bacteria
}

\author{
BY RENANA BEN-GURION \\ Israel Institute for Biological Research, Ness-Ziona, Israel
}

(Received 10 February 1962)

\begin{abstract}
SUMMARY
When colicinogenic female bacteria are crossed with non-colicinogenic males, all the genes of the male chromosome can enter into the zygote without necessarily killing it. There is a great difference with regard to the number of certain recombinants tested, derived from crosses of the type Hfr col- $\times \mathrm{F}^{-} \mathrm{col}^{+}$, as compared to their numbers in crosses of the type Hfr $\mathrm{col}^{-} \times \mathrm{F}^{-} \mathrm{col}^{-}$. In certain cases this difference was reduced when the zygotes were incubated at $28^{\circ}$ instead of the standard temperature of $37^{\circ}$. It was found that resistance to colicines is not always an all-or-none phenomenon. There are different degrees of colicine resistance and those mutants which show complete resistance by the standard tests are still found to be sensitive under more rigorous conditions. In the case of colicine $\mathrm{B}$ the sensitivity of these semi-resistant mutants is greater at $37^{\circ}$ than at $28^{\circ}$.
\end{abstract}

\section{INTRODUCTION}

An asymmetry in crosses between colicinogenic and non-colicinogenic bacteria was first described by Fredericq \& Betz-Bareau (1953). On crossing $\mathbf{F}+\mathrm{col}^{+} \times \mathrm{F}^{-} \mathrm{col}^{-}$, the $\mathrm{col}^{+}$property was transferred to some of the recombinants, but when the $\mathrm{F}^{+}$parent was $\mathrm{col}^{-}$and the $\mathrm{F}^{-}$parent $\mathrm{col}^{+}$, the $\mathrm{col}^{-}$property did not appear in any of the recombinants. It was concluded that the colicinogenic factor is not a part of the bacterial chromosome, but a cytoplasmic particle, a plasmagene. Alföldi et al. (1957, 1958), demonstrated that the col $\mathrm{E} 1$ factor is a part of the Hfr chromosome and is transferred to the recombinants in a normal fashion, when on the Hfr chromosome. However, they claimed that when the Hfr parent was noncolicinogenic, and its chromosome had the $\mathrm{col}^{-}$property, the entry of this factor into recipient bacteria which were $\mathrm{col}^{+}$was lethal for the zygote. They called this phenomenon 'lethal zygosis'. The present paper describes a study of several crosses of the Hfr $\mathrm{col}^{-} \times \mathrm{F}^{-} \mathrm{col}^{+}$type.

\section{METHODS}

Organisms. All the strains used were derived from non-lysogenic derivatives of Escherichia coli $\mathbf{K}$ 12. Strain TR 21 is a derivative of strain Y 20; it requires threonine + leucine + thiamine (thrleuthi), it is streptomycin-sensitive $(s t r-s)$, produces colicines $E 2$ and I (Fredericq, 1955) and is $F^{-}$. Strain TR 24 is a derivative of strain 112-12, it requires cysteine + histidine (cys his), is resistant to streptomycin (str-r), produces colicine B (Fredericq, 1955) and is F-. Strain TR 25 is also a derivative of strain 112-12, (cys his str-r), produces colicine $\mathrm{K}$ (Fredericq, 1955) and is $\mathrm{F}^{-}$. (These 
strains were kindly supplied by Professor P. Fredericq, Université de Liège, Belgium.) Strain Hfr C requires thiamine (thi) and is streptomycin-sensitive. Strain Hfr P4X6 requires methionine (met) and is streptomycin-sensitive. PA417 requires arginine + histidine + proline (arg his pro), is streptomycin-resistant and $\mathrm{F}^{-}$. (These strains were kindly supplied by Dr F. Jacob, Institut Pasteur, Paris.)

Media. Nutrient broth was Difco nutrient broth. Nutrient agar was nutrient broth $+2 \%$ Difco agar. Minimal medium had the following composition: $\mathrm{Na}_{2} \mathrm{HPO}_{4}$, $0.7 \%(\mathrm{w} / \mathrm{v}) ; \mathrm{KH}_{2} \mathrm{PO}_{4}, \mathbf{0 . 3} \%(\mathrm{w} / \mathrm{v}) ; \mathrm{NH}_{4} \mathrm{Cl}, 0.1 \%(\mathrm{w} / \mathrm{v}) ; \mathrm{NaCl}, 0.05 \%$ (w/v); $\mathrm{CaCl}_{2}, 10^{-4} \mathrm{M} ; \mathrm{MgSO}_{4}, 10^{-8} \mathrm{M}$; glucose, $0 \cdot 4 \%(\mathrm{w} / \mathrm{v})$; amino acids (when added) $0.016 \%(\mathrm{w} / \mathrm{v})$, thiamine $5 \mu \mathrm{g} . / \mathrm{ml}$. Glucose, amino acids, thiamine and $\mathrm{CaCl}_{2}$ were autoclaved separately. Minimal medium agar was prepared by adding $4 \%(\mathrm{w} / \mathrm{v})$ agar, autoclaved separately, to double-strength minimal medium. When streptomycin was used, $200 \mu \mathrm{g}$. $/ \mathrm{ml}$. was added to the medium. Bacto Penassay Broth was from Difco.

Experimental procedure. Strains were stored on nutrient agar slopes at $4^{\circ}$. Cultures for use were propagated from such stock by overnight growth in liquid medium (nutrient broth + thiamine; minimal medium; or Penassay broth) with aeration at $37^{\circ}$. Samples $(0.5 \mathrm{ml}$.) of each parent culture were diluted the following morning into 4.5 vol. of fresh medium at $37^{\circ}$ and incubated at this temperature on a rotary shaker for 3 to $4 \mathrm{hr}$. until the population density of bacteria reached about 1 to $2 \times 10^{8}$ organisms $/ \mathrm{ml}$. To cross the organisms, $1.8 \mathrm{ml}$. of $\mathrm{F}^{-}$culture were mixed with $0.2 \mathrm{ml}$. of $\mathrm{Hfr}$ culture, the mixture then incubated at $37^{\circ}$ on a very slow rotary shaker for $\mathbf{2} \mathrm{hr}$., and the culture then diluted and plated on suitable medium to detect selected recombinants. The plates were incubated at $37^{\circ}$ for $48 \mathrm{hr}$. and the colonies counted. Variations from this procedure are mentioned in the text.

\section{RESULTS}

\section{The preparation of mutants resistant to various colicines}

In order to cross $\mathrm{Hfr}$ bacteria with colicinogenic $\mathbf{F}$ - bacteria it was necessary to prepare Hfr mutants resistant to the colicine produced by the $\mathbf{F}^{-}$parent. To prepare such mutants, Hfr organisms were spread as a uniform layer on nutrient agar plates, on top of which single drops of suspensions of colicinogenic bacteria, sterilized by chloroform, were added. The colicine-resistant mutants were obtained from the few colonies which grew in the inhibition zones thus produced. These were selected, purified twice by re-streaking, checked for purity and used for further work. In the case of colicines $B$ and $K$, the resistant mutants of strain $\mathbf{H f r} \mathbf{C}$ prepared in this way showed only partial resistance. They were only resistant to the colicines in a chloroformed culture which had stood for more than 1 day in the refrigerator, but were not resistant to a completely fresh chloroformed culture, or when colicinogenic bacteria were grown over them. Mutants partially resistant to colicine $\mathrm{B}$ were sensitive to this colicine when tested at $37^{\circ}$ and much less so at $28^{\circ}$; the original strains were equally sensitive to the colicine at both temperatures. These partially resistant mutants were incubated again with freshly prepared colicines and resistant colonies isolated as before. These new mutants were resistant to the colicines even when tested by growing colicinogenic bacteria over them at $37^{\circ}$ and at $28^{\circ}$ and were used for further work. 
The survival of $\mathrm{col}^{+} \boldsymbol{F}^{-}$bacteria mixed with an excess of $\mathrm{col}^{-} \boldsymbol{H}$ fr bacteria

$\mathrm{F}^{-} \mathrm{col}^{+}$str-r bacteria were mixed in nutrient broth with an excess of $\mathrm{Hfr} \mathrm{col}^{-}$ $s t r-s$ bacteria $\left(1 \times 10^{7} \mathrm{~F}-\right.$ bacteria for $1-2 \times 10^{8} \mathrm{Hfr}$ bacteria) and the mixture agitated very gently at $37^{\circ}$. At intervals samples were plated on nutrient agar supplemented with streptomycin. Table 1 gives the number of viable $\mathbf{F}^{-}$str-r bacteria at different times. In each experiment the Hfr organism used was the Hfr mutant resistant to the colicine (S) which the corresponding $\mathrm{F}^{-}$organism produced. As seen from Table 1, no noticeable killing effect by $\mathrm{Hfr} \mathrm{col}^{-}$bacteria was observed with the three colicinogenic strains used with two different Hfr strains.

Table 1. Survival of $\mathrm{F}^{-} \mathrm{col}^{+}$bacteria when mixed with excess of $\mathrm{H} f \mathrm{rol} \mathrm{col}^{-}$organisms

Suspensions of different mutants of streptomycin-sensitive HfrC and Hfr P4 46 were mixed in broth with different colicinogenic streptomycin-resistant $\mathrm{F}^{-}$organisms. The proportion was $1-3 \times 10^{8} \mathrm{Hfr}$ organisms/ml. for $1-3 \times 10^{7} \mathrm{~F}^{-}$organisms/ml. The mixture was agitated at $37^{\circ}$, samples taken at different times and counted on nutrient agar supplemented with streptomycin.

F-str-r strain

TR 24 colB +

PA $417 \mathrm{col}^{-}$

TR 24 colB +

PA $417 \mathrm{col}^{-}$

TR 21 colE $2^{+} \& \mathrm{I}^{+}$

PA $417 \mathrm{col}^{-}$

TR $21 \operatorname{col} \mathrm{E}^{+} \& \mathrm{I}^{+}$

PA $417 \mathrm{col}^{-}$

TR 25 colK+

PA $417 \mathrm{col}^{-}$

TR 25 colK+

PA 417 col- $^{-}$
Hfr str-s strain col-

HfrC $\operatorname{colB}^{\mathrm{R}}$ (colicine B-resistant)

HfrC $\operatorname{colB}^{\mathrm{R}}$ (colicine B-resistant)

Hfr P4X6 colB ${ }^{R}$

Hfr P4X6 colB ${ }^{R}$

Hfr P4X6 col (E 2 and I)

Hfr P 4X6 col (E 2 and I)

HfrC $\operatorname{col}(\mathbf{E} 2 \& I)^{\mathrm{R}}$

HfrC $\operatorname{col}(\mathbf{E} 2 \& \text { I })^{\mathrm{R}}$

HfrC $\operatorname{colk}^{\mathrm{R}}$

$\mathrm{HfrC} \operatorname{colK}^{\mathrm{R}}$

Hfr P4X6 colK $^{\mathrm{R}}$

Hfr P4X6 colK $^{\text {R }}$
No. of surviving str- $r$ $\begin{array}{cc}\text { Time } & \text { organisms } \\ \text { (min.) } & \times 10^{-7} / \mathrm{ml} .\end{array}$

(min.)

$\mathbf{2} \cdot \mathbf{5}$

$2 \cdot 9$

$2 \cdot 7$

$\mathbf{3 \cdot 2}$

2.9

$\mathbf{3 \cdot 5}$

1

1.5

$1 \cdot 8$

3.1

2.9

3.9

3. 8

5.4

3.2

4-3

4.3

6

$2 \cdot 9$

4.3

3.4

5

3. 6

5.4

3.6

$4 \cdot 9$ 


\section{Crosses of non-colicinogenic $H$ fr donors and colicinogenic $F^{-}$recipients producing colicine $B$}

To be sure that all the genes of the chromosome entered the zygotes, we used two different Hfr donor strains, so that the chromosomes entered into the $\mathbf{F}^{-}$ recipients from different directions (Jacob \& Wollman, 1957, 1958). These donor strains were: strain HfrC, whose chromosome enters the zygote in the order thr leu pro gal his str arg thi; strain Hfr P4X6 whose transfer of the genetic characters proceeds in the order pro leu thr thi arg str his gal. In all crosses we selected a marker for amino acid independence which is negative in the recipient and positive in the donor, namely his. The recombinants thus selected must have been derived from zygotes which received a segment of the donor chromosome containing at least the part from 0 (where it starts to enter the zygote) until the selected marker his $^{+}$. Two his ${ }^{+}$str-r recombinants, one from each donor, must derive from two zygotes that together contained at least one complete copy of the $\mathrm{Hfr}$ chromosome with all its genes.

Table 2. A comparison of the numbers of his ${ }^{+}$str-r recombinants with colicinogenic (colicine $B$ ) and non-colicinogenic recipients, incubated at $37^{\circ}$

Parent suspensions were prepared in the usual way and mated in broth + thiamine, in defined minimal medium or in Penassay broth. After $2 \mathrm{hr}$., the mixture of mating organisms was plated and counted on streptomycin minimal media supplemented with the amino acids required by the parents, but omitting histidine.

\section{Parents mated}

HfrC (ColB ${ }^{R}$ str-s) $\times$ TR 24 (cys his str-r colB $\left.\left.{ }^{+}\right)\right\}$ HfrC $\left(\operatorname{colB}{ }^{\mathrm{R}}\right.$ str-s) $\times$ PA 417 (arg his pro str-r col ${ }^{-}$) Hfr P4 $\times 6$ (colB ${ }^{R}$ str-s met) $\left.\times\right)$ TR 24 (cys his str-r colB ${ }^{+}$) Hfr P4 $\times 6\left(\right.$ colB ${ }^{R}$ str-s met $\left.) \times\right)$ PA 417 (arg his pro str-r col-)
Mated in

broth + thiamine defined medium $t$ broth + thiamine defined medium broth + thiamine Penassay broth broth + thiamine Penassay broth

No. of his ${ }^{+} s t r-r$ recombinants*

\begin{tabular}{lc}
\multicolumn{1}{c}{1} & 2 \\
$2.7 \times 10^{8}$ & $2.4 \times 10^{8}$ \\
$7 \cdot 1 \times 10^{4}$ & $4.4 \times 10^{4}$ \\
$1 \times 10^{4}$ & $2.4 \times 10^{4}$ \\
$3.7 \times 10^{5}$ & $1.5 \times 10^{5}$ \\
$1.8 \times 10^{4}$ & $1.1 \times 10^{8}$ \\
$5.3 \times 10^{4}$ & $\cdot$ \\
$1.5 \times 10^{4}$ & $1.9 \times 10^{3}$ \\
$\mathbf{3 . 8} \times 10^{4}$ & $\cdot$
\end{tabular}

* Five-fold dilutions of the mating suspensions were plated on 3 plates for each dilution.

$\dagger$ During this work it was found that crosses in defined medium yielded more recombinants so that the crosses towards the end of this work were carried out in defined medium.

As recipient for the first series of experiments the colicinogenic strain TR 24 cys his colB was used. Each cross had a control cross with the non-colicinogenic strain PA 417 ( $a r g$ his pro $\mathrm{col}^{-}$) as recipient bacteria. The donors used were the mutants of Hfr resistant to colicine $B$ produced by the recipient bacteria. The results of some typical experiments are summarized in Table 2. It can be seen that some $h i s^{+} s t r-r$ recombinants were obtained from crosses of the colicinogenic recipient with each of the Hfr strains. In other experiments of the same sort similar results were obtained. The number of recombinants is smaller by a factor of 4 to 20 in crosses of the $\mathrm{HfrC}$ parent with the $\mathrm{col}^{+}$recipient, as compared to the crosses of HfrC with the $\mathrm{col}^{-}$recipient; no such difference was seen when Hfr P 4X6 was used.

The effect of temperature on recombinant frequencies. We changed the usual pro- 
cedure for the detection of recombinants by incubation on the selective medium at room temperature for $24 \mathrm{hr}$. The results of two typical experiments are recorded in Table 3. Incubation of the plates at room temperature first resulted in a significant increase in the number of his ${ }^{+}$str-r recombinants of the $\mathrm{HfrC} \mathrm{col}^{-} \times \mathrm{col}^{+}$ crosses, but no increase in the number of his str-r recombinants in the HfrC $\mathrm{col}^{-} \times \mathrm{col}^{-}$crosses. The ratio of the number of recombinants at the two temperatures varied in other experiments of the same sort from $1: 3$ to $1: 8$ for $\mathrm{col}^{-}$by $\mathrm{col}^{+}$crosses.

Table 3. Number of his ${ }^{+}$str-r recombinants when incubated for 24 hr. at $23^{\circ}-24^{\circ}$ and then at $37^{\circ}$

\begin{tabular}{|c|c|c|c|c|}
\hline \multirow{3}{*}{$\begin{array}{l}\text { Temperature of incubation } \\
\text { of the selective plates }\end{array}$} & \multicolumn{4}{|c|}{ Number of $h^{2}{ }^{+} s t r-r$ recombinants } \\
\hline & \multicolumn{2}{|c|}{ Cross of $\mathrm{HfrC} \mathrm{col}^{-} \times \mathrm{TR} 24 \mathrm{colB}^{+}$} & \multicolumn{2}{|c|}{ Cross of HfrC $\mathrm{col}^{-} \times$PA $417 \mathrm{col}^{-}$} \\
\hline & Exp. 1* & Exp. 2 & Exp. 1 & Exp. 2 \\
\hline $\begin{array}{l}37^{\circ} \text { all the time } \\
24 \mathrm{hr} \text {, at } 23-24^{\circ} \text { and }\end{array}$ & $\begin{array}{l}1.7 \times 10^{3} \\
6.8 \times 10^{3}\end{array}$ & $\begin{array}{l}6.6 \times 10^{3} \\
4.9 \times 10^{4}\end{array}$ & $\begin{array}{l}1.8 \times 10^{4} \\
1.8 \times 10^{4}\end{array}$ & $\begin{array}{l}2 \times 10^{5} \\
2 \cdot 1 \times 10^{5}\end{array}$ \\
\hline
\end{tabular}

* In experiment 1 the crosses were made in nutrient broth + thiamine; in experiment 2 in defined medium.

When the effect of other temperatures was examined it was found that preincubation at $28^{\circ}$ had about the same effect as pre-incubation at room temperature, while pre-incubation at $18^{\circ}$ or at $10^{\circ}$ had a smaller effect. To determine whether the increase in the number of his str-r recombinants formed at room temperature was due to a factor formed at room temperature, or rather to one destroyed at $37^{\circ}$, the selective plates were incubated first at $37^{\circ}$ for $24 \mathrm{hr}$. and then at room temperature, as compared with plates incubated first at room temperature. It was found that initial incubation at $37^{\circ}$ destroyed the ability to form more recombinants on subsequent incubation at room temperature.

The inheritance of the $\mathrm{col}^{+}(B)$ character in $\mathrm{col}^{-} \times \mathrm{col}^{+}$crosses. his ${ }^{+}$str-r recombinants from $\mathrm{col}^{-} \times \mathrm{col}^{+}(\mathrm{B})$ crosses were picked from the plates, resuspended in the same selective medium and tested for colicinogeny; 150 recombinants selected at $37^{\circ}$ and 250 recombinants selected at $28^{\circ}$ were tested; all were colicinogenic. To separate the recombinants from the zygotes and from other segregants so as to decrease the time during which they could be infected with the colicinogenic factor, the plates were respread after incubation for a few hours. A large number of single colonies from plates incubated at $37^{\circ}$ and $28^{\circ}$ were tested for colicinogeny; all were found positive. Another experiment to separate the segregants was carried out in liquid media; in this case also only colicinogenic recombinants were found.

Crosses of non-colicinogenic Hfr cells and colicinogenic $\boldsymbol{F}^{-}$producing colicine $\boldsymbol{K}$. Crosses were carried out between the recipient bacterium TR 25 cys his (colK) and non-colicinogenic Hfr organisms. Each cross had a control cross with the noncolicinogenic strain PA 417 (arg his pro) as recipient. The donors used for these crosses were mutants resistant to colicine $\mathrm{K}$. The results of two typical experiments are summarized in Table 4. It appears that some his $^{+}$str-r recombinants were obtained when TR $25 \mathrm{colK}^{+}$was crossed with $\mathrm{HfC}$ and when TR $25 \mathrm{colK}^{+}$was crossed with Hfr P4X6. hut that there were more recombinants when the cross 
was of the type $\mathrm{col}^{-} \times \mathrm{col}^{-}$. The presence of the colK' factor in the $\left[\mathrm{F}^{-}\right.$parent decreased the yield of recombinants with each of the two Hfr donor strains used. With HfrC the factor of decrease varied from $1: 10$ to $1: 30$, and with $P 4 \times 6$ the factor varied from $1: 1$ to $1: 4$. Crosses between TR 25 colK $^{+}$and $\mathrm{HfrC}$ colK ${ }^{\mathrm{R}}$ were made, comparing the number of the recombinants for the case in which the zygotes were incubated at $28^{\circ}$ with the number found when the zygotes were incubated at $37^{\circ}$ (Table 5). When the crosses were of the type $\mathrm{col}^{-} \times \mathrm{colK}^{+}$, incubation of the zygotes at $28^{\circ}$ increased very little the number of recombinants. The number of his ${ }^{+}$str-r recombinants from the $\mathrm{col}^{-} \times \mathrm{col}^{-}$cross was much higher, even then. his str-r recombinants from $\mathrm{col}^{-} \times \mathrm{colK}^{+}$crosses were tested for colicinogenicity, 100 recombinants selected at $37^{\circ}$ and 90 selected at $28^{\circ}$ were tested; all were colicinogenic.

Table 4. Comparison of the number of his ${ }^{+}$str-r recombinants with colicinogenic recipients (producing colicine $\boldsymbol{K}$ ) and non-colicinogenic recipients

No. of histstr-r recombinants.

Mating was done in defined medium

Parents

HfrC $\operatorname{colK} K^{\mathrm{R}} \times$ colK + TR 25

HfrC colK $^{\mathrm{R}} \times \mathrm{col}^{-}$PA 417

Hfr P4X6 colK ${ }^{\mathrm{R}} \times \mathrm{TR}_{25}$ colK ${ }^{+}$

Hfr P4X6 colK ${ }^{R} \times$ PA 417 col- $^{-}$

$\begin{array}{cl}\text { Exp. 1 } & \text { Exp. 2 } \\ 4.9 \times 10^{8} & 9 \times 10^{3} \\ 4.5 \times 10^{4} & 2.8 \times 10^{5} \\ 1.5 \times 10^{3} & 8.8 \times 10^{3} \\ 6.7 \times 10^{8} & 5.4 \times 10^{3}\end{array}$

Table 5. The number of his ${ }^{+}$str-r recombinants when the zygotes were incubated at $\mathbf{2 8}^{\circ}$ for the first $24 \mathrm{hr}$.

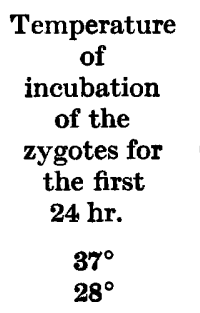

\begin{tabular}{|c|c|c|c|c|c|}
\hline \multicolumn{6}{|c|}{ No. of $h i s^{+}$str-r recombinants* } \\
\hline \multicolumn{3}{|c|}{ Crosses of $\mathrm{HfrC}$ colK ${ }^{\mathrm{R}} \times \mathrm{TR} 25 \mathrm{colK}^{+}$} & \multicolumn{3}{|c|}{ Crosses of $\mathrm{HfrC}$ colK $^{\mathrm{R}} \times \mathrm{PA} 417 \mathrm{col}^{-}$} \\
\hline Exp. 1 & Exp. 2 & Exp. 3 & Exp. 1 & Exp. 2 & Exp. 3 \\
\hline $\begin{array}{l}3 \times 10^{8} \\
8 \times 10^{5}\end{array}$ & $\begin{array}{l}9 \times 10^{3} \\
1.1 \times 10^{4}\end{array}$ & $\begin{array}{r}4.9 \times 10^{3} \\
6 \times 10^{3}\end{array}$ & $\begin{array}{l}1 \times 10^{5} \\
9 \times 10^{4}\end{array}$ & $\begin{array}{l}2.8 \times 10^{5} \\
2.4 \times 10^{5}\end{array}$ & $\begin{array}{l}4.5 \times 10^{4} \\
4.3 \times 10^{4}\end{array}$ \\
\hline
\end{tabular}

The fate of the donor organisms in crosses of the $\mathrm{col}^{-} \times \mathrm{col}^{+}$type as compared to their fate in crosses of the $\mathrm{col}^{-} \times \mathrm{col}^{-}$type. Table 6 presents two typical experiments that give the number of viable donor organisms in crosses of the $\mathrm{col}^{-} \times \mathrm{col}^{-}$type, as compared to their number in crosses of the $\mathrm{col}^{-} \times \mathrm{col}^{+}$type. The ratios of viable counts of $\mathrm{HfrC}$ before and after the crosses ranged as follows: (1) $\mathrm{HfrC} \operatorname{colB}^{\mathrm{R}} \times$ $\mathrm{F}^{-} \operatorname{colB}^{+} 1: 2$ to $1: 1 \cdot 3$, compared to $1: 2 \cdot 3$ to $1: 1.5$ when crossed with $\mathrm{F}^{-} \operatorname{col}^{-}$; (2) HfrC $\operatorname{colK}^{\mathrm{R}} \times \mathrm{F}^{-}$colK $K^{+} 1: 0 \cdot 14$ to $1: 1.4$ compared to $1: 1.6$ to $1: 2.5$ when crossed with $\mathrm{F}^{-} \operatorname{col}^{-}$; (3) HfrC. $\operatorname{col}\left(\mathrm{E} 2\right.$ and I) ${ }^{\mathrm{R}} \times \mathrm{F}^{-} \operatorname{col~E~} 2^{+}$and $\mathrm{I}^{+} 1: 2$, i.e. the same as when crossed with $\mathrm{F}^{-}$col $^{-}$. It appears that colicinogenic females which produced colicines $\mathrm{E} 2$ and I did not influence the survival and growth of $\mathrm{HfrC}$ organisms during the period allowed for mating, and that colicinogenic females producing colicine B did not have much influence on the male survival and growth, whereas colicinogenic females which produced colicine $K$ affected much more the survival and growth of HfrC organisms mated with them. 
Table 6. The survival of $\mathrm{H} f \mathrm{r}$ col- bacteria when crossed with $\mathrm{col}^{+}$females compared to their survival when crossed with col- recipients

Suspension of Hfr organisms (resistant to the colicines produced by the corresponding females) were mixed in defined medium with colicinogenic female bacteria. The proportion was approximately $1 \mathrm{Hfr}$ organism to 5-10 $\mathrm{F}^{-}$organisms $/ \mathrm{ml}$. The mixture was agitated at $37^{\circ}$, samples taken before and after the cross and counted on minimal medium + thiamine. The plates were incubated at $37^{\circ}$.

Hfr strain

HfrC $B^{R}$

$\mathrm{HfrC} \mathrm{B}^{\mathrm{R}}$

*HfrC $\mathbf{K}^{\mathrm{R}}$

HfrC $\mathbf{K}^{\mathrm{R}}$

HfrC (E 2 and $I)^{R}$

HfrC (E 2 and I) ${ }^{R}$
F- strain

TR 24 colB $^{+}$

PA $417 \mathrm{col}^{-}$

TR 25 colK $^{+}$

PA 417 col-

TR 21 cole $2^{+}$and $I^{+}$

PA 417 col- $^{-}$
No. of surviving $\mathrm{Hfr}$ organisms $/ \mathrm{ml}$. in the mating mixture

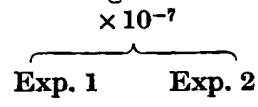

(hr.)

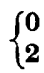

$\left\{\begin{array}{l}0 \\ 2\end{array}\right.$

so

$\left\{\begin{array}{l}0 \\ 2\end{array}\right.$

$\left\{\begin{array}{l}0 \\ 2\end{array}\right.$

$\left\{\begin{array}{l}0 \\ 2\end{array}\right.$

$\left\{\begin{array}{l}0 \\ 2\end{array}\right.$
1.8

3.5

1.8

$4 \cdot 2$

2.5

0.33

2.5

$5 \cdot 2$

$\mathbf{3} \cdot \mathbf{9}$

$\mathbf{7 \cdot 3}$

$\mathbf{3} \cdot \boldsymbol{9}$

$\mathbf{7} \cdot \mathbf{1}$

* For experiment 1 , one mutant of $\mathrm{HfrC}^{\mathrm{R}}$ was used; for experiment 2 another mutant was used.

\section{DISCUSSION}

The above experiments show that when recipient bacteria are colicinogenic for

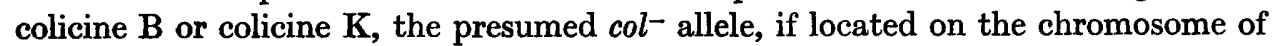
an Hfr bacterium (Alföldi et al. 1958), does not always kill the zygote when it enters. This was definitely proved by crossing each colicinogenic $\mathbf{F}^{-}$bacterium with two different Hfr donors whose directions of gene transfer are opposite to each other. Thus, the histstr-r recombinants selected in both crosses must have been derived from zygotes which received a segment of the donor chromosome containing at least the part from 0 to $\mathrm{his}^{+}$(Fig. 1).

Although the entry of the col- factor into a zygote does not necessarily kill it, it was found that the number of histstr-r recombinants in a cross of $\mathrm{col}^{-} \times \mathrm{col}^{+}$type was decreased as compared with the number in a cross of the $\mathrm{col}^{-} \times \mathrm{col}^{-}$type. The presence of the col $K$ factor in the $F^{-}$parent decreased the yield of recombinants with each of the two Hfr donor strains used, as compared to the yield of these recombinants in the presence of $\operatorname{col} B$ factor in the $\mathrm{F}^{-}$parent. The difference in the yield of recombinants with the HfrC donor was even bigger when compared to the number of these recombinants derived from an $\mathrm{F}^{-} \mathrm{col}^{-}$recipient. It could be argued that the non-colicinogenic and the colicinogenic strains compared as $\mathrm{F}^{-}$partners do not differ merely by the presence or absence of the $\mathrm{col}^{-}$factor concerned and, therefore, the F-col strain (PA 417) is not an adequate control. However, strain 112-12 $\mathrm{col}^{-}$was not available and attempts to cure the colicinogenic strains of their 
colicinogenic factors or to infect another K 12 strain (PA $417 \mathrm{col}^{-}$) with any of the colicinogenic factors K or B were unsuccessful. Strain PA 417 used in this work could be regarded as a reference strain and the two 112-12 col strains which differ from each other only by the presence of different col factors can be compared with this reference.

The number of his ${ }^{+s t r}-r$ recombinants in $\mathrm{col}^{-} \times \mathrm{col}^{+}$crosses increased when the zygotes were incubated at a temperature lower than $37^{\circ}$. In crosses of $\mathrm{HfrC} \times$ TR $24($ colB $)$, the number of his $^{+}$str-r recombinants was nearly the same as in the $\mathrm{HfrC} \times \mathrm{col}^{-}$crosses, when the zygotes were incubated at $28^{\circ}$. The smaller number of

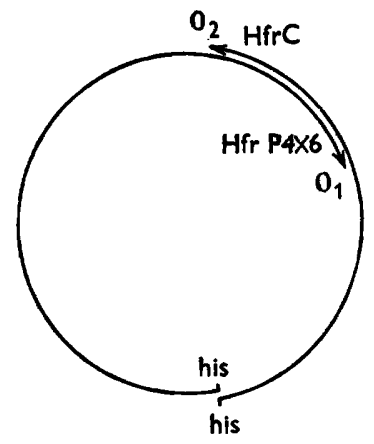

Fig. 1. The parts of the chromosome that are sure to enter the his $^{+}$recombinants in the two crosses: from $0_{2}$ to his in the cross with Hfr P 4X6; from $0_{2}$ to his in the cross with HfrC. Two such complementary recombinants contain at least one complete copy of the Hfr chromosome with all its genes.

recombinants from Hfr $\mathrm{col}^{-} \times \mathrm{col}^{+}$crosses could be explained by the observations that when bacteriocinogenic bacteria become non-bacteriocinogenic, they lose their immunity and become sensitive to the bacteriocin which they have produced (Fredericq, 1948; Hertman \& Ben-Gurion, 1959). If a recombinant inherits from the Hfr parent the $\mathrm{col}^{-}$, but not the colicine-resistant allele, it should become sensitive to the colicine, since the colicinogenic $\mathbf{F}^{-}$were not resistant but only immune, as the colicinogenic strains used were prepared from a sensitive 112-12 strain (Professor Fredericq, personal communication). Such a $\mathrm{col}^{-}$recombinant should be sensitive to the colicine that other bacteria produce. This could account wholly or partly for the smaller number of histstr-r recombinants that come out of such crosses, since some of them could be killed by the colicine. The hypothesis is perhaps supported by the fact that one does get more recombinants when the zygotes are incubated at $28^{\circ}$, as it has been shown in one bacteriocinogenic system that the bacteriocin produced was far more active towards sensitive organisms at $37^{\circ}$ than at $28^{\circ}$ (Ben-Gurion \& Hertman, 1958). With colicinogenic bacteria for colicine $B$, we have found, using the semi-resistant mutants, an indication that there is a higher sensitivity at $37^{\circ}$ than at $28^{\circ}$.

In crosses of $\mathrm{HfrC}$, where the $\mathrm{F}^{-}$is colicinogenic for $\mathrm{K}$, there are far less $h_{i s^{+}}$ str- $r$ recombinants than with $F^{-}$colicinogenic for $B$. Here we found that although by the standard tests the Hfr mutants were resistant to colicine $K$, viable counts of the Hfr parents showed that the Hfr organisms were inhibited and some of them 
killed by the presence of the $\mathrm{F}^{-}$colicinogenic bacteria. This could also account, at least partly, for the small number of recombinants that arise from such crosses. The fact that all the recombinants tested were colicinogenic could be explained, perhaps, by the episomal characteristic of colicines. Since the zygotes contained these episomes to start with, it is possible that all the col- segregants were infected. Another fact emerges from the experiments described, namely that resistance to some colicines is not an all-or-nothing phenomenon. We have seen that resistance to colicine $\mathbf{K}$ or $\mathbf{B}$ could be acquired by two mutational steps and even then some Hfr mutants grew much less in the presence of colicinogenic bacteria than in the presence of non-colicinogenic bacteria, creating the impression that they were still partly sensitive to it.

The author is grateful to Miss Karla Schajevitz for excellent technical assistance.

\section{REFERENCES}

Alföldi, L., Jacob, F. \& Wollman, E. L. (1957). Zygose létale dans des croisements entre souches colicinogènes et non-colicinogènes d' Escherichia coli. C.R. Acad. Sci., Paris, 244, 2974.

Alföldd, L., JACOB, F., Wollman, E. L. \& MAZE, R. (1958). Sur le déterminisme génétique de la colicinogenie. C.R. Acad. Sci., Paris, 246, 353.

Ben-Gurion, R. \& Hertman, I. (1958). Bacteriocin-like material produced by Pasteurella pestis. J. gen. Microbiol. 19, 289.

Frederice, P. \& Betz-Bareau, M. (1953). Transfert génétique de la propriété colicinogène en rapport avec la polarité F des parents. C.R. Soc. Biol., Paris, 147, 2043.

FredericQ, P. (1948). Antibiotiques réciproques chez les Enterobacteriaceae. Rev. belge Path. (Suppl. 4), 19, 1.

Frederice, P. (1955). Induction de la production de colicine et de bactériophage par irradiation ultraviolette de souches colicinogènes et lysogènes d'Escherichia coli. C.R. Soc. Biol., Paris, 149, 2028.

Hertman, I. \& Ben-Gurion, R. (1959). A study on pesticin biosynthesis. J. gen. Microbiol. 21, 135.

JaCOB, F. \& Wolman, E. L. (1957). Analyse des groupes de liaison génétique de différentes souches donatrices d'Escherichia coli K 12. C.R. Acad. Sci., Paris, 245, 1840.

JACOB, F. \& Wolmman, E. L. (1958). Genetic and physical determination of chromosomal segments in $E$. coli. In 'The biological replication of macromolecules'. Symp. Soc. exp. Biol. 12, 75. 